\title{
Argan Tree (Argania spinosa (L.) Skeels) Mapping Based on Multisensor Fusion of Satellite Imagery in Essaouira Province, Morocco
}

\author{
Aicha Moumni $\mathbb{D},{ }^{1}$ Tarik Belghazi $\mathbb{D}^{2},{ }^{2}$ Brahim Maksoudi $\mathbb{D}^{2}, 2$ \\ and Abderrahman Lahrouni ${ }^{1}{ }^{1}$ \\ ${ }^{1}$ Faculty of Science Semlalia, Cadi Ayyad University, 40000, Marrakesh, Morocco \\ ${ }^{2}$ Regional Center of Forest Research, 40000, Marrakesh, Morocco \\ Correspondence should be addressed to Aicha Moumni; ach.moumni@gmail.com
}

Received 18 April 2021; Revised 6 July 2021; Accepted 11 September 2021; Published 5 October 2021

Academic Editor: Stelios M. Potirakis

Copyright (c) 2021 Aicha Moumni et al. This is an open access article distributed under the Creative Commons Attribution License, which permits unrestricted use, distribution, and reproduction in any medium, provided the original work is properly cited.

\begin{abstract}
Tree species identification and their geospatial distribution mapping are crucial for forest monitoring and management. The satellite-based remote sensing time series of Sentinel missions (Sentinel-1 and Sentinel-2) are a perfect tool to map the type, location, and extent of forest cover over large areas at local or global scale. This study is focused on the geospatial mapping of the endemic argan tree (Argania spinosa (L.) Skeels) and the identification of two other tree species (sandarac gum and olive trees) using optical and synthetic aperture radar (SAR) time series. The objective of the present work is to detect the actual state of forest species trees, more specifically the argan tree, in order to be able to study and analyze forest changes (degradation) and make new strategies to protect this endemic tree. The study was conducted over an area located in Essaouira province, Morocco. The support vector machine (SVM) algorithm was used for the classification of the two types of data. We first classified the optical data for tree species identification and mapping. Second, the SAR time series were used to identify the argan tree and distinguish it from other species. Finally, the two types of satellite images were combined to improve and compare the results of classification with those obtained from single-source data. The overall accuracy (OA) of optical classification reached $86.9 \%$ with a kappa coefficient of 0.84 and declined strongly to $37.22 \%$ (kappa of 0.29 ) for SAR classification. The fusion of multisensor data (optical and SAR images) reached an OA of $86.51 \%$. A postclassification was performed to improve the results. The classified images were smoothed, and therefore, the quantitative and qualitative results showed an improvement, in particular for optical classification with a highest OA of $89.78 \%$ (kappa coefficient of 0.88 ). The study confirmed the potential of the multitemporal optical data for accurate forest cover mapping and endemic species identification.
\end{abstract}

\section{Introduction}

The monitoring of forest cover plays a crucial role in biodiversity, feedstock, and water cycle, etc. Therefore, tree species discrimination is necessary and fundamental for this process. Satellite imagery together with machine learning techniques have become an irreplaceable tool for tree species mapping. Passive and/or active sensors provide valuable geospatial information to identify tree types. Recently, machine learning algorithms are techniques that have been successfully used based on remote sensing data for tree type classification [1]. Current satellite sensors, such as Sentinel missions, facilitated the tree species mapping at local as well as national scale.

In literature, the most remote sensing data used for forest type mapping is optical imagery. For such data, the forest type classification is based on reflected spectral features that are acquired by optical sensors. However, the different forest type classes (tree crops) can be characterized by similar spectral signatures. Thus, tree species identification becomes 
difficult and complicated using only spectral features [2]. Weather is one of the factors that caused such a confusion due to the dependence of optical data on sunlight. SAR imagery is a supplement of optical data due to its capacity to acquire images in all-day and in all-weather conditions through penetrating rain and clouds. In 2004, Touzi et al. [3] used the C band of SAR data to discriminate forest tree species and figured out that the information of $\mathrm{VV}, \mathrm{HH}$, and $\mathrm{VH}$ polarizations identified better the forest trees without leaves. Another study [4] showed that information extracted from SAR imagery can discriminate easily between forest and nonforest types.

In addition, the texture features $[5,6]$ extracted from gray-level cooccurrence matrix (GLCM) have been widely investigated in forest type classification using SAR imagery [6-9]. However, the results of land cover/land use (LC/LU) classification using SAR data are not consistent [9-11]. Therefore, many studies indicated that combining SAR features with optical data can improve the forest type classification results [12, 13]. Machine learning algorithms are powerful methods for forest and crop classification. SVM classification algorithm has proven its effectiveness for classifying forest tree species using satellite imagery [14-16].

The endemic Moroccan tree called argan (Argania spinosa) covered 950,000 ha in 2010 [17]. It is part of the semiarid Mediterranean domain in southwest Morocco in transition towards the Sahara [18]. The zone was declared a UNESCO MAB (Man and the Biosphere Reserve) in 1998. Argan trees have provided multiple ecosystem products and services including the provision of fruits from which argan oil is produced. Argan is a slow-growing tree with shrubby architecture which has a lifespan of around 200 years [19]. Argan trees have traditionally provided multiple ecosystem products and services including the provision of fruits from which argan oil is produced; leaves and young shoots eaten by sheep, goats, and camels; and wood for fiber and fuel [20].

During the last century, more than half of the argan forest of Morocco disappeared, mainly in the plains, and its mean density fell from 100 to less than 30 stumps/ha to meet the growing fuel needs of major Moroccan cities [21]. Recent work distinguishes between lowland and mountain argan plantations, where ecological and economic conditions differ significantly [22]. The former seems very threatened, as it has great agricultural potential and absorbs most of the emigration from mountain areas. Socioeconomic changes and the farms' modernisation since the 1980s have led to a cumulative $2.6 \%$ reduction in forest cover over the last 17 years [23]. In mountain argan groves, where the user population retains a traditional pattern of use, several trends can be discerned. Therefore, these several factors caused degradation, desertification, and problems in the natural regeneration of the argan population $[24,25]$. To overcome these problems, specific management strategies are needed, in such a way that the state of forest resources should be assessed with detailed and accurate geospatial distribution of different forest tree species and, more specifically, argan trees.

The estimate of forest cover and its mapping relies mainly on fieldwork and ground surveys, which require cost and time. However, high-resolution satellite data such as
Landsat and Sentinel images are available and provide huge amounts of data regularly on large areas in short time and remotely. Satellite image-based land cover land use mapping, generally, still have some challenges despite the improvement of spatial and temporal resolution [26-29]. Particularly, forest tree species discrimination can face the presence of similar classes in the study area and/or the presence of several features within the same pixel, contributing to spectral confusion between different forest over types $[30,31]$. In this contest, we attempted to identify the argan tree from other forest species based on the classification of time series of SAR data and its derived products (GLCM texture features: correlation variance and mean), the classification NDVI time series derived from optical images, and finally, the classification of combined multisensor time series data using an SVM classifier.

The achievement of the objective of the present work is illustrated in four steps, namely, (i) to model and discriminate the phenological evolution of the Moroccan argan tree from other tree species using S2-derived NDVI time series; (ii) to map the spatial extent of forest cover and identify its tree species; (iii) to evaluate the tree species mapping using optical data, SAR data, and the fusion of the two types of satellite imagery; and (iv) to evaluate and assess the potential of SAR data to improve the tree species classification performance and overcome the confusion constraints.

\section{Background}

Morocco is one of the few countries in North Africa to have a diverse range of endemism and biodiversity [32]. The only species in its genus, Argania spinosa (L.) Skeels, belongs to the Sapotaceae, a tropical and subtropical tree family. It is endemic only to Morocco, where it grows in arid and semiarid climates with 150 to $400 \mathrm{~mm}$ of rainfall per year. It is a slow-growing spiny tree that can reach a maximum height of around $10 \mathrm{~m}$ (Figure 1$)$. The leaves are small $(20 \mathrm{~mm})$, with a spatulated shape and an entire margin. Despite having evergreen foliage, leaves may be shed entirely or partially in response to summer stress.

In 1998, M'Hirit et al. classified it as a facultative summer semideciduous tree. Flowering takes place mostly in the spring, with a lot of variation between individuals, and there is a secondary peak in the autumn. As a result, fruit production continues over a long period of time, with fruits appearing in various stages of ripening from April to September [20]. The fruits are stalkless drupes that look like olives and have a hard endocarp that protects an oil-rich kernel. In different cameras, one endocarp can contain up to four kernels, although the normal number is one.

It is a multipurpose forest tree (forest, fruit, and fodder) of great importance to the country, both biologically, phylogenetically, and ecologically, as well as economically and socially [33]. It has significant medicinal and therapeutic properties due to the oil extracted from its fruits $[34,35]$. Furthermore, it is highly sought after in cosmetics as a skin and hair revitalizing agent. This ecosystem is based on a balance of resources and human exploitation, and it also plays 


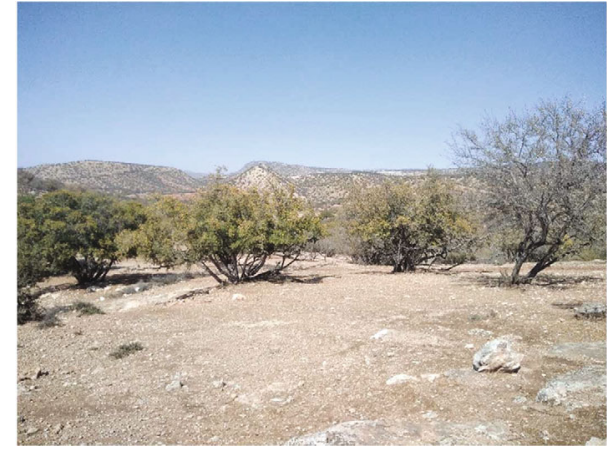

FIGURE 1: Argan tree in Essaouira region (07/09/2019).

an important role in the fight against desertification and erosion.

Regardless of the various roles played by this species, the threat of argan degradation is a major concern for both the general public and scientists [36]. Artificial regeneration is the main way to ensure the survival of the argan tree in particular and forest cover in general [37, 38]. Figure 2 illustrates some reforested areas around Smimou in Essaouira province.

With the absence of accurate and detailed mapping of the argan forest in the region, as well as an assessment of recent changes, we use the potential of satellite images acquired from different sensors to detect the actual state of forest species trees and, more specifically, the argan tree. Forest cover mapping is a practical tool for decision making in forest management. Moreover, it is a means for the definition of the area's objectives and management operations, to establish a framework of intervention for the manager.

\section{Materials and Methods}

3.1. Experimental Site. The test site is an area of approximately 2000 ha across Smimou village in Essaouira of Morocco (Figure 3). This rural district is considerably large and varied, with the mountain range covering a large part of it. The most famous mountain and the highest peak in Essaouira province (912 m), is Jbel Amsittene [39]. The Smimou zone is characterized by an arid to semiarid climate. During the year, the temperature generally varies from $10^{\circ} \mathrm{C}$ to $22^{\circ} \mathrm{C}$ and is rarely below $8^{\circ} \mathrm{C}$ or above $26^{\circ} \mathrm{C}[40$, 41]. The mean temperature is around $20^{\circ} \mathrm{C}$. The rains are irregular with an annual average of $300 \mathrm{~mm}$.

Indeed, the climate is also diverse in terms of both temperature and precipitation. This is due to the oceanic (Atlantic) setting on one side and the height of the mountains on the other. Precipitation varies by $48.6 \mathrm{~mm}$ between the driest and the wettest month.

3.2. Reference Data. The field data are used to extract profiles and train the classifiers. Moreover, those samples are exploited to validate the classification results. In collaboration with the team of the Forestry Research Center (CRF), samples were collected during two field campaigns in 2019, and completed by samples extracted using the archive of very high spatial resolution images from Google Earth. The surveyed plots are accompanied by descriptions informing about the land cover type, and they are randomly split into two groups: calibration samples and validation samples. The land cover typology was grouped into eight main classes that were selected in terms of abundance over the area. This typology contains argan, sandarac gum, fallow, bare soil, olive, argan + sandarac gum, noncrop, and agricultural lands. Table 1 illustrates the number of training and validation samples for each land cover type.

Reference date was used also for the extraction of the temporal NDVI profiles of land cover types, in order to determine the different phenological states of the argan tree and other tree species

\subsection{Satellite Data and Data Processing}

3.3.1. Optical Imagery. The most convenient satellite data is determined by a number of factors, including (i) spatial resolution, (ii) revisit time, (iii) image availability and cost over the study area, and (v) study area characteristics [42]. S2 is primarily aimed at freely offering high spatiotemporal resolution optical imagery for operational land cover and change detection mapping [43]. These data can be downloaded on the Theia Land Service website [44], which produces and distributes level 2A products, corrected atmospherically using the MAJA/MACCS software developed thanks to the coordination between Cnes/Cesbio and DLR [45-48].

For the present study, S2 images have been downloaded from December 2018 to December 2019 over the Smimou experimental site. The 35 downloaded images, covering the whole year of 2019 and well distributed over the agricultural seasons, have been used to derive the Normalized Difference Vegetation Index (NDVI) time series.

This index is the most commonly used vegetation index in remote sensing. NDVI [49] is a normalized index that generates an image showing the degree of vegetation cover (biomass). The absorption of chlorophyll pigment in the red channel and the high reflectivity of plant matter in the near infrared (NIR) channel are used to create this index, which is based on the comparison in two channels of a multispectral raster data set $[50,51]$. NDVI is calculated based on the normalized difference of the NIR and R spectral bands and illustrated as follows:

$$
\mathrm{NDVI}=\frac{\mathrm{NIR}-\mathrm{R}}{\mathrm{NIR}+\mathrm{R}}
$$

This index generates values between -1 and 1, mainly representing the vegetation cover, where negative values are mainly generated by clouds, water, and snow and values close to zero are mainly generated by rock and bare soil. The very low NDVI values ( 0.1 and below) correspond to waste rock, sand, or snow surfaces. Intermediate values $(0.2$ to 0.3 ) represent areas of shrubs and grasslands, while high values (0.6 to 0.8$)$ indicate temperate or tropical rainforests. The transformation of the images into NDVI layers was carried out for the whole series of 35 images, in order to extract the phenological evolution of the tree species and the other 

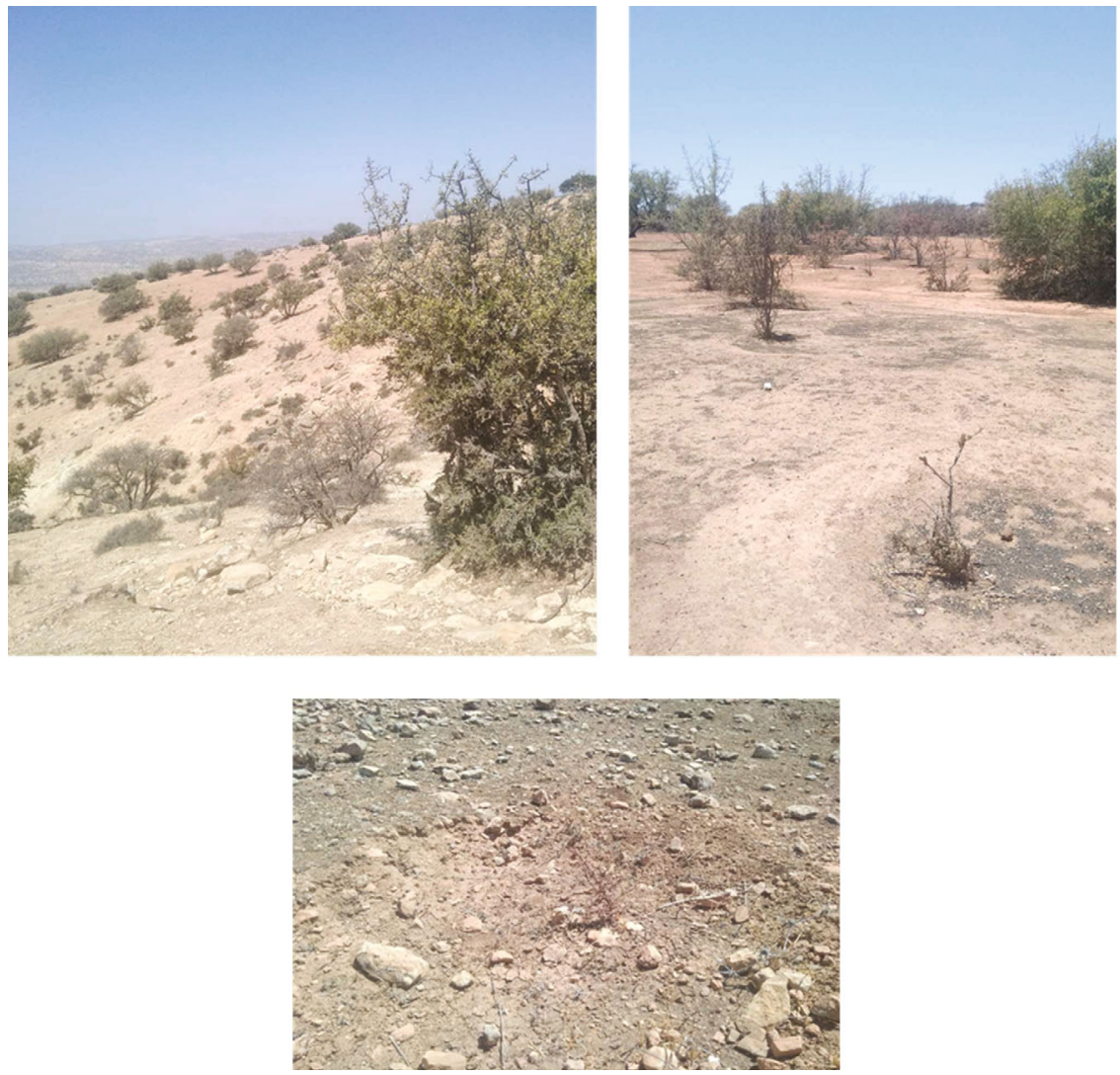

Figure 2: Reforested areas in Essaouira (07/09/2019).

land cover classes selected to be identified and mapped in this study.

3.3.2. SAR Imagery. Sentinel-1 (S1) is a two-satellite constellation that orbits the Earth in 6 days. The twin Sentinel-1A/B constellations use synthetic aperture radar (SAR) imaging to acquire imagery regardless of weather conditions.

S1 images were acquired in the Ground Range Detected (GRD) format and interferometric wide (IW) swath mode with dual polarization (VV and $\mathrm{VH}$ ) through the PEPS CNES website https://peps.cnes.fr/. The S1 products offered by the PEPS platform are calibrated and orthorectified on the S2 grid in order to facilitate the joint use of the two missions [52-57]. Two SAR images were downloaded each month to coincide with key dates in terms of crop vegetative cycles. This produced a set of 22 SAR images (Figure 4).

S1 images were preprocessed using the Sentinel Application Platform (SNAP) and ENVI software as follows: (i) the removal of the speckle noise using the enhanced Lee filter, (ii) the conversion of SAR bands' pixel values to $\mathrm{dB}$ values to facilitate the interpretation and the analysis of data, and (iii) the extraction of texture features using a gray-level cooccurrence matrix (GLCM).

(1) Speckle Noise Filtering and Conversion to $d B$. The main issue in SAR imaging classification and interpretation is the speckle noise effect, which is caused by coherent interference of the wave reflected from several basic scatterers [58].
Speckle noise removal filtering is a technique for improving image quality by decreasing the speckle noise effect.

The enhanced Lee filter has been chosen in this study to minimize the speckle effect on the images without loss of information. According to the literature, it is one of the most used filters to reduce speckle noise in SAR remote sensing data $[59,60]$.

We have applied the enhanced Lee filter [61] implemented in ENVI software to the S1 images acquired in VV and $\mathrm{VH}$ polarizations, with a window size of $5 \times 5[62,63]$. The filtered images were then converted into decibels $(\mathrm{dB})$ using the following:

$$
X=10 \times \log 10(x),
$$

where $x$ is the value of each pixel, $X$ is the value converted to $\mathrm{dB}$.

(2) Texture Feature Extraction. SAR imagery contains texture information [5, 64]. Image classification will benefit greatly from SAR texture information features. New texture images can be reconstructed using the spatial information in the SAR image. Texture features provide details from neighboring pixels, which is useful in discriminating the various crop types found in agricultural fields [65]. 


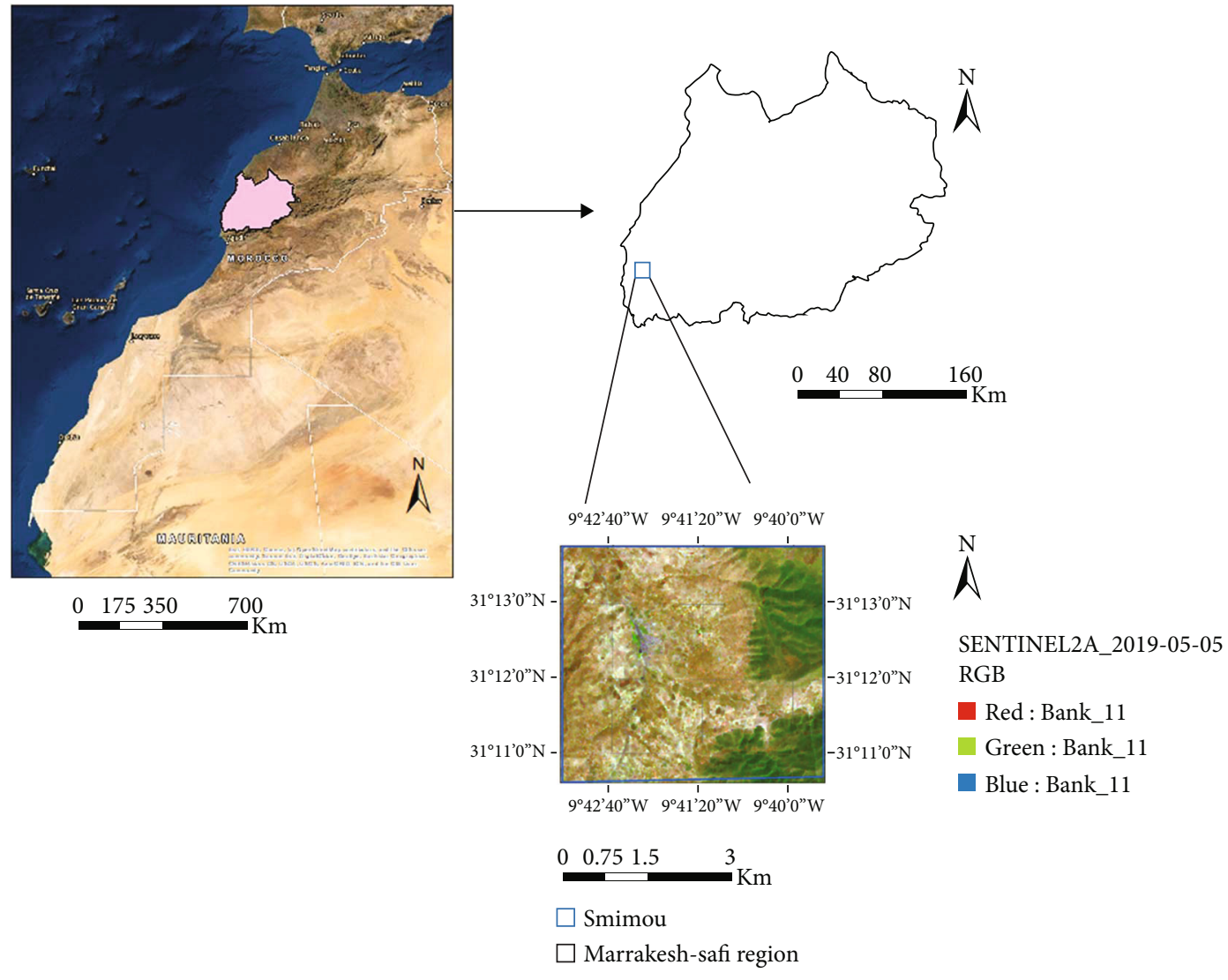

FIgURE 3: Study area location.

TABLE 1: Detailed description of reference data used for tree species classification.

\begin{tabular}{|c|c|c|c|c|c|}
\hline & \multicolumn{2}{|c|}{ Calibration } & \multicolumn{2}{|c|}{ Validation } & \multirow{2}{*}{ Total } \\
\hline & Sample numbers & Pixel numbers & Sample numbers & Pixel numbers & \\
\hline Argan tree & 56 & 255 & 103 & 134 & 159 \\
\hline Olive tree & 79 & 201 & 38 & 136 & 117 \\
\hline Sandarac gum tree & 23 & 343 & 44 & 243 & 67 \\
\hline Argan + sandarac gum & 17 & 662 & 55 & 266 & 72 \\
\hline Agricultural land & 13 & 272 & 24 & 138 & 37 \\
\hline Fallow & 9 & 239 & 22 & 109 & 31 \\
\hline Bare soil & 28 & 657 & 26 & 101 & 54 \\
\hline Non-crop & 9 & 189 & 28 & 133 & 37 \\
\hline Total & 234 & & 340 & & 574 \\
\hline
\end{tabular}

A gray-level cooccurrence matrix (GLCM) is considered one of the most popular techniques used for texture analysis. It is calculated based on a statistical method, also known as the gray-level spatial dependence matrix. GLCM is capable of assessing texture features by taking into account the spatial relationship between pixels and their surroundings $[66,67]$.

From many proposed statistical texture methods, the gray-level cooccurrence matrix (GLCM) is one of the most powerful for land cover/land use (LC/LU) mapping $[68,69]$.
The texture analysis was applied with VV and VH polarizations using the Sentinel toolbox called SNAP (SeNtinel Application Platform) based on GLCM statistics. GLCM is a probability measure of two gray levels separated by a given distance occurring in the same orientation. According to the literature [70-73], the most common and popular GLCM texture features used for tree type discrimination are as follows: correlation, mean, and variance. These three texture measurements were calculated and used for the present study. 
Acquisition dates

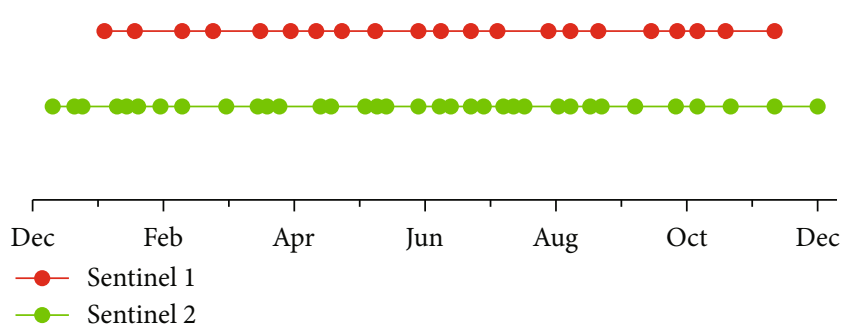

FIGURE 4: Distribution of radar and optical image acquisition dates.

The correlation function defines the similarity between the elements of columns or rows in GLCM and is a measure of the image's gray-tone linear dependencies. The GLCM correlation feature can be calculated as follows:

$$
\frac{\sum_{i, j=0}^{N-1} i P_{i, j}-\mu_{x} \mu_{y}}{\sigma_{x} \sigma_{y}} .
$$

The GLCM mean value is more than just the average of all original pixel values; each pixel value is weighted based on how frequently it occurs in combination with a specific neighbor pixel value. The expression of the mean is illustrated as follows:

$$
\sum_{i, j=0}^{N-1} i P_{i, j}
$$

The variance texture parameter targets the SAR image's partial characteristic. It can be computed as follows:

$$
\sum_{i, j=0}^{N-1} i P_{i, j}(i-\mu) 2,
$$

where

(i) $P_{i, j}$ is a normalized gray-tone spatial dependency matrix such as $\sum_{i, j=0}^{K-1} i P_{i, j}=1$

(ii) $i$ and $j$ represent, respectively, the rows and columns for the mean, variance, and correlation measurements

(iii) $\mu$ is the mean for the variance texture measurement

(iv) $N$ is the number of distinct gray levels in the quantized image

(v) $\left(\mu_{x}, \mu_{y}\right)$ and $\left(\sigma_{x}, \sigma_{y}\right)$ are the means and standard deviations of $P_{x}$ and $P_{y}$ respectively, for the correlation texture measure [74]

3.4. Methodology. The methodological approach followed in this work (Figure 5) consists of 5 main steps:

(1) Data acquisition
(2) Data preprocessing

(3) Extraction and analysis of profiles and classification

(4) Accuracy assessment and postclassification

(5) Comparison, analysis, and map production

3.4.1. SVM Classification. SVM is one of the most appealing algorithms for remotely sensed data classification because of the benefits of generalization even with limited training samples, which is common in remote sensing data processing $[26,75]$. Furthermore, because SVM is a supervised nonparametric statistical learning method, it does not require a training set that strictly follows the standard independent and identical distribution. The benefits of SVM stem from two factors: transforming the original space training set into a very high dimensional new space and discovering a large linear margin boundary in the new space [76]. SVM is a classifier based on the structural risk minimization theory that is aimed at reducing generalization error by maximizing margins on training data [77]. SVM classifiers can use a variety of kernel functions. However, only four of them have been widely used to classify satellite data: polynomial, linear, radial basis function ( $\mathrm{RBF}$ ), and sigmoid kernels [77]. In the present study, The SVM-RBF kernel was selected and used for all image classifications as one of the most effective machine learning algorithms for classifying forest tree species using satellite imagery [14-16].

3.4.2. Classification Scenarios. ENVI Classification Scenarios is a professional software for classifying satellite imagery using both unsupervised and supervised algorithms. For this work, we have limited ourselves to using supervised methods, in particular the support vector machines (SVM). The techniques generally provide better results in the production of land cover maps [78-80]. As a first step, we started by classifying the time series of NDVI, VV, VH, and $\mathrm{VH} / \mathrm{VV}$. We then combined the data from the two sensors to explore different possible scenarios (combinations). Table 2 describes these scenarios in the order followed during the image classification step.

3.4.3. Performance Assessment. Evaluation of classification performance was done by comparing images and by calculating the accuracy of the land use classification using statistical tools such as the confusion matrix and the kappa index $(K)$ introduced by Cohen [81], which is used to validate and estimate the precision in the vegetation classification scheme [80]. Its formula is as follows:

$$
\text { Kappa }=\frac{P_{0}-P_{c}}{P_{p}-P_{c}},
$$

where

(i) $P_{0}$ : is equal to the actual percentage obtained from classification of land covers; it is equal to the quotient of the sum of the diagonal digits of the matrix with the total number of observations 


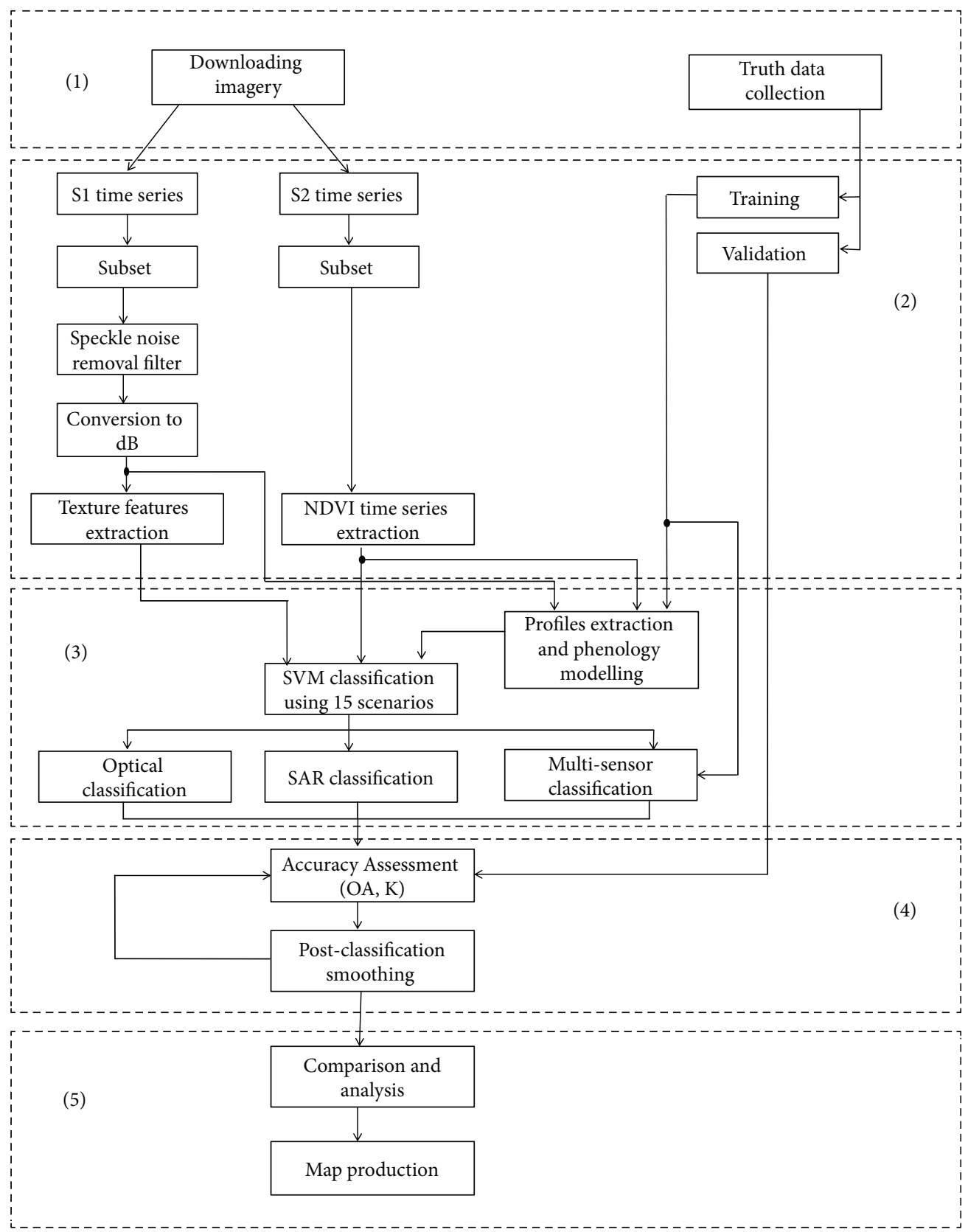

FIgURE 5: Methodological approach followed for the present study.

(ii) $P_{c}$ is the estimate of the probability of obtaining a correct classification. For a correct classification, the value of $P_{c}$ is generally lower than $P_{0}$

(iii) $P_{p}$ : is the percentage obtained when the classification is perfect

Confusion matrices have been calculated in order to evaluate the results, these matrices reveal not only the general errors made at the level of each class during interpretation but also errors due to confusion between land use classes. The mathematical expression used to calculate the $\mathrm{OA}$ of the classification is given by the average of the percentages of correctly classified pixels:

$$
\mathrm{OA}=\frac{\sum_{i=1}^{r} X_{i i}}{N} \times 100
$$

where

(i) $X_{i i}$ is the number of diagonal pixels (i.e., correctly classified)

(ii) $N$ is the total number of pixels

(iii) $R$ is the total number of classes

3.4.4. Postclassification: Smoothing. After the classification, the obtained images showed a lack of sharpness in the 
TABLE 2: Scenarios created for the classification step.

\begin{tabular}{|c|c|c|c|}
\hline Scenario & Bands & Satellite sensor & Type \\
\hline 1 & NDVI & S2 & Optical \\
\hline 2 & VV & $\mathrm{S} 1$ & SAR \\
\hline 3 & VH & S1 & SAR \\
\hline 4 & VH/VV & S1 & SAR \\
\hline 5 & $\mathrm{VV}, \mathrm{VH}$ & S1 & SAR \\
\hline 6 & $\mathrm{VV}, \mathrm{VH} / \mathrm{VV}$ & S1 & SAR \\
\hline 7 & VH, VH/VV & S1 & SAR \\
\hline 8 & $\mathrm{VV}, \mathrm{VH}, \mathrm{VH} / \mathrm{VV}$ & S1 & SAR \\
\hline 9 & Texture & S1 & SAR \\
\hline 10 & Texture, VH, VH/VV & S1 & SAR \\
\hline 11 & Texture, VH, VV & S1 & SAR \\
\hline 12 & Texture, VV, VH/VV & S1 & SAR \\
\hline 13 & NDVI, VV & $\mathrm{S} 1$ and $\mathrm{S} 2$ & Optical and SAR \\
\hline 14 & NDVI, VH & $\mathrm{S} 1$ and $\mathrm{S} 2$ & Optical and SAR \\
\hline 15 & NDVI, VH/VV & $\mathrm{S} 1$ and $\mathrm{S} 2$ & Optical and SAR \\
\hline 16 & NDVI, VV, VH & $\mathrm{S} 1$ and $\mathrm{S} 2$ & Optical and SAR \\
\hline 17 & NDVI, VV, VH/VV & $\mathrm{S} 1$ and $\mathrm{S} 2$ & Optical and SAR \\
\hline 18 & NDVI, VH, VH/VV & $\mathrm{S} 1$ and $\mathrm{S} 2$ & Optical and SAR \\
\hline 19 & NDVI, VV, VH, VH/VV & $\mathrm{S} 1$ and $\mathrm{S} 2$ & Optical and SAR \\
\hline 20 & NDVI, texture & $\mathrm{S} 1$ and $\mathrm{S} 2$ & Optical and SAR \\
\hline 21 & NDVI, texture, VH, VH/VV & $\mathrm{S} 1$ and $\mathrm{S} 2$ & Optical and SAR \\
\hline 22 & NDVI, texture, VV & $\mathrm{S} 1$ and $\mathrm{S} 2$ & Optical and SAR \\
\hline
\end{tabular}

definition of the classified plots; the images always seem "noisy." We then apply a smoothing filter, called majority/minority analysis [82], to the images using the ENVI software. This analysis filters the image by replacing the value of the center pixel in a window with a size of $n \times n$ (where $n$ has to be defined) with the majority value in that window. In order to avoid "oversmoothing," we have chosen a window with a size of $3 \times 3$.

\section{Results and Discussion}

\subsection{Analysis of Temporal Profiles}

4.1.1. NDVI Profiles. For each of the selected classes, the NDVI, VV, VH, and VH/VV profiles were calculated, in order to study the possible confusions and/or separability to be expected between these different classes, and to be able to interpret and analyze the classification results. The temporal evolution of the NDVI profiles allows the modeling of land cover type dynamics, and particularly the phenological evolution of the different vegetative classes, which makes them relatively interpretable. On the other hand, the SAR profiles are more complex for the vegetative classes, reflecting the evolution of the proportion of the backscattered signal, mainly influenced by the surface roughness of the canopy as well as its water content. Figure 6 shows, for each of the selected classes, the temporal evolution of NDVI, and that of the C-band backscattered signals (in $\mathrm{VV}, \mathrm{VH}$, and $\mathrm{VH} / \mathrm{VV}$ polarizations).
NDVI is a measurement of the normalized difference between the energy emitted in infrared and red by surface objects, when applied to vegetation communities. This index establishes a value indicating the importance or dominance of vegetation in a given area. For annual crops, as an example, the start of the season (i.e., the start date of the vegetation growth phase) is the point at which the rate of increase in NDVI values is higher than previous successive observations during the vegetation growth period. While the end of the season is defined as the point in the maturity period when a significant drop in NDVI is observed.

These changes can be seen in Figure 6 for fallow and agricultural land, where the NDVI spectral profiles of these crops illustrate their seasonal aspects. The amplitude of the graphs becomes important during periods of vegetation development. Agricultural lands in this region grow vegetables that develop in January, but they represent only small plots with produce intended for local consumption. Fallow land resembles cereals that are cultivated in early December, reach their maximum development in late March, and are harvested in mid-May and early June at the latest, which is due to the inputs of winter rains.

Argan, sandarac gum, argan + sandarac gum, and olive form a group of tree species present in the study area; however, we have separated them. The NDVI value of these classes is generally all year round greater than 0.2 (Figure 6), given that they are perennial crops. Decreases in the NDVI values of these trees in summer are due to water stress resulting from lack of water and increased temperatures during 

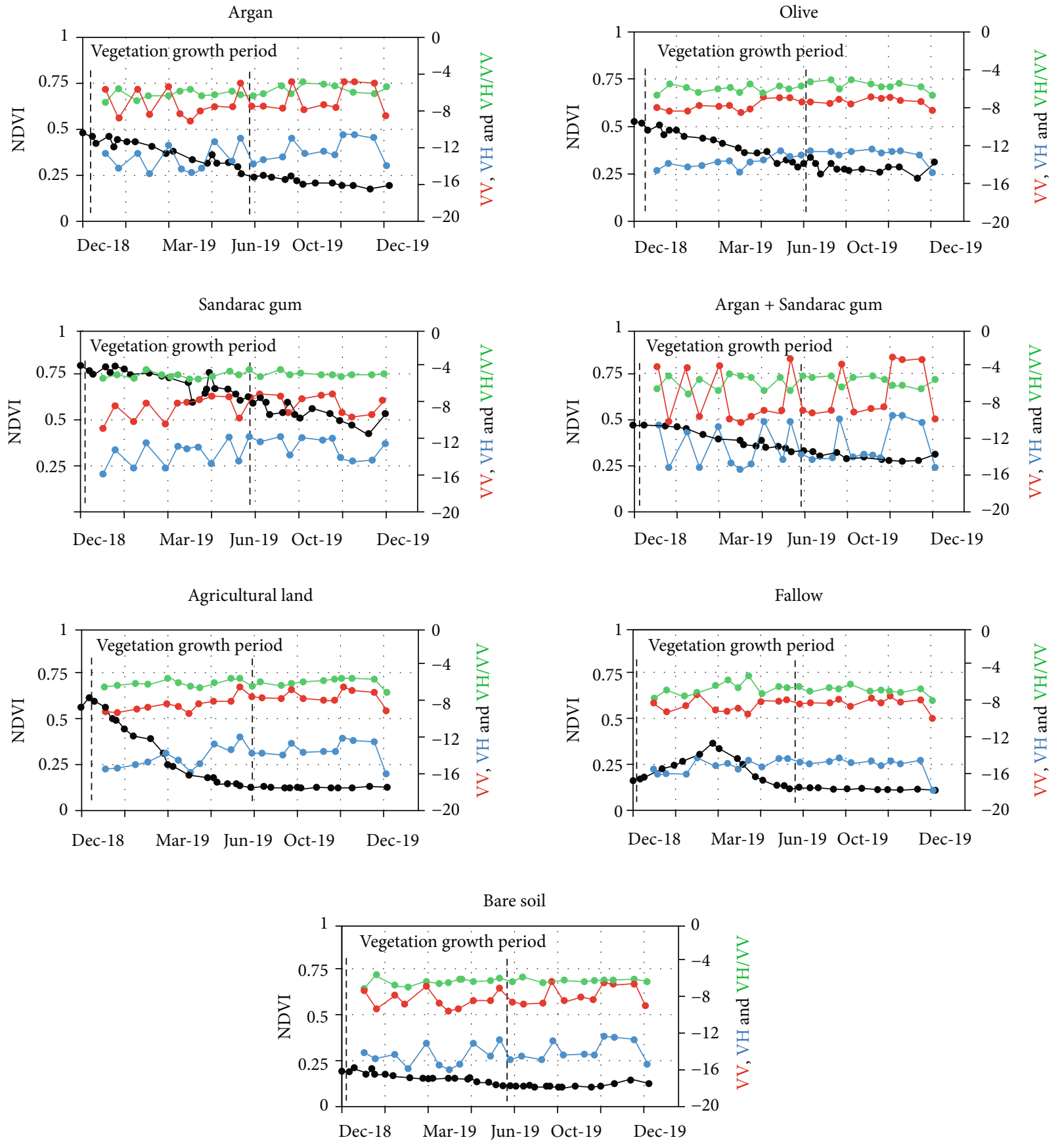

FIGURE 6: NDVI, VV, VH, and VH/VV profiles of the different selected classes present in the Smimou zone.

this period, and also sometimes due to loss of leaves through pruning. The temporal profile of the mixture (argan + sandarac gum) is approximately the same as that of the olive trees.

The classes of bare soil and noncrop are relatively easy to detect due to the absence of vegetation translated by NDVI values of no more than 0.20 (Table 3 ). These two classes have been combined into one class called "bare soil."

4.1.2. VV, VH, and VH/VV Profiles. The VV, VH, and VH/VV profiles presented in Figure 6 illustrate the temporal evolution in intensity (radar backscatter coefficient $\sigma$ expressed in $\mathrm{dB}$ of the $\mathrm{VV}, \mathrm{VH}$, and $\mathrm{VH} / \mathrm{VV}$ polarizations) of the 7 cover types selected: agricultural land, olive, sandarac gum, fallow, argan, argan + sandarac gum, and bare soil. First of all, we can clearly see that for all the classes studied (Figure 6), the values of intensity in parallel polarization VV (values between $-3 \mathrm{~dB}$ and $-10 \mathrm{~dB}$ ) are above those in cross polarization $\mathrm{VH}$ (values between $-9 \mathrm{~dB}$ and $-17 \mathrm{~dB}$ ), while the values of intensity of the $\mathrm{VH} / \mathrm{VV}$ ratio (in $\mathrm{dB}$ ) are positive and above those of the two previous polarizations (varying between $4 \mathrm{~dB}$ and $7 \mathrm{~dB}$ ), and this for all the classes. Moreover, even if the graphs look similar, the ranges 
TABLE 3: NDVI ranges and amplitudes of all classes during 2019.

\begin{tabular}{lccc}
\hline Class & Max & Min & Amplitude \\
\hline Argan & 0.48 & 0.17 & 0.31 \\
Sandarac gum & 0.81 & 0.43 & 0.38 \\
Olive & 0.53 & 0.22 & 0.31 \\
Fallow & 0.37 & 0.11 & 0.26 \\
Argan + sandarac gum & 0.48 & 0.28 & 0.20 \\
Agricultural land & 0.62 & 0.12 & 0.50 \\
Bare soil & 0.20 & 0.10 & 0.10 \\
\hline
\end{tabular}

of the signal values are different. We can also notice the oscillatory behavior of the argan and sandarac gum classes and their mixture, the reasons for which are still unknown.

In contrast to NDVI profiles, radar profiles seem to be more complicated to interpret. The two main physical variables influencing the backscattering process are water content and roughness, and since this latter varies from one class to another, in addition to the fact that the region is dry, it can be said that the similarity between the backscattered signals of the different classes is due to the low water content of the observed surfaces. This hypothesis is supported by several bibliographical works [83-85] aimed at mapping the rice fields, and which have shown that the temporal change in rice field backscatter is very high compared to other classes, given the amounts of water present on flooded fields.

4.2. Classification Accuracies. Table 4 presented the results corresponding to the scenarios of uncombined Sentinel products. The classification results of the products from each of the two sensors S1 and S2 confirm the superiority of the optical data and the SVM algorithm in terms of LC/LU classification and performance.

The OA resulting from the classification of the NDVI time series is $86.90 \%(K=0.84)$, while the best values of OA that have been obtained by classifying the SAR time series and more precisely scenarios (VV and $\mathrm{VH}$ ) and $(\mathrm{VV}, \mathrm{VH}$, and $\mathrm{VH} / \mathrm{VV})$ are only $33.85 \%(K=0.24)$ and $32.68 \%(K=0.22)$, respectively. We note that the addition of the $\mathrm{VH} / \mathrm{VV}$ to the $\mathrm{VH}$ or VV band increases the accuracy by about $5 \%$ to $6 \%$, while the inclusion of textural features improved the classification to $37.22 \%(K=0.29)$. Taking into consideration that SAR sensors are not primarily intended for land cover mapping, the classification of SAR products in this area presents much lower results than those found by optical data (NDVI).

The classification results of combined optical and SAR products are grouped in Table 5.

The combination of S1 and S2 products, compared to S2 classification, does not improve the classification accuracy. On the contrary, in the study area, the integration of the two types of satellite data gave practically the same results as the classification of optical data.

In order to visually compare the quality of the classified images, we present in Figure 7 the images obtained for the scenarios reached good OA.
TABLE 4: Classification results of uncombined sentinel products.

\begin{tabular}{lcc}
\hline Scenarios & OA (\%) & SVM \\
\hline NDVI & 86.90 & $K$ \\
VV & 27.14 & 0.84 \\
VH & 26.40 & 0.15 \\
VH/VV & 28.95 & 0.15 \\
VH, VV & 33.85 & 0.17 \\
VH, VH/VV & 32.15 & 0.24 \\
VV, VH/VV & 31.86 & 0.22 \\
VH, VV, VH/VV & 32.68 & 0.21 \\
Texture & 36.65 & 0.22 \\
Texture, VH, VH/VV & 37.22 & 0.28 \\
Texture, VH, VV & 35.91 & 0.28 \\
Texture, VV, VH/VV & 36.58 & 0.27 \\
\hline
\end{tabular}

TABle 5: Classification results of combined S1 and S2 images.

\begin{tabular}{lcc}
\hline Scenarios & OA & SVM \\
\hline NDVI, VH & 82.46 & $K$ \\
NDVI, VV & 86.51 & 0.79 \\
NDVI, VH/VV & 84.98 & 0.84 \\
NDVI, VH, VV & 83.03 & 0.82 \\
NDVI, VH, VH/VV & 81.97 & 0.80 \\
NDVI, VV, VH/VV & 84.27 & 0.78 \\
NDVI,VH, VV, VH/VV & 81.47 & 0.80 \\
NDVI, texture & 58.62 & 0.78 \\
NDVI, texture, VH, VH/VV & 67.24 & 0.52 \\
NDVI, texture, VV & 68.02 & 0.62 \\
\hline
\end{tabular}

Indeed, we observed differences between the classifications of S1 and S2 products. The quality of the classified SAR images is lower than that of the classified NDVI image in terms of sharpness even if the speckle effect has been reduced after applying the filter. This can be explained by the huge confusion of the argan class with the olive tree, which appears to be dominant on the maps resulting from the classification of SAR products. The combined products, as expected, had quite sharp images, which is due to the complementary contribution of the optical data. The presence of isolated pixels on homogeneous plots over the entire area contributes to the "noisy" appearance of the classified SAR products. Therefore, we have tried to improve the quality of these images and the accuracy of the results by applying a postprocessing which consists of smoothing the classified products.

Visually, the quality of image classification has improved as shown in Figure 8. The smoothed product looks more like the classified image from the NDVI time series. This process has been applied to all scenarios (optical and SAR classified images) and has given satisfactory results. Table 6 shows the $\mathrm{OA}$ and $K$ coefficient for these scenarios before and after the smoothing process has been applied. 


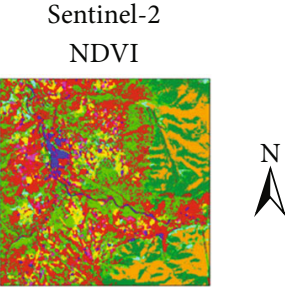

Sentinel-2 \& Sentinel-1

$\mathrm{VV}, \mathrm{VH}$

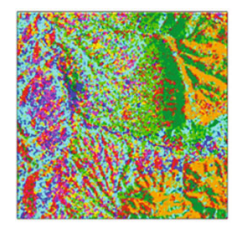

Sentinel-1

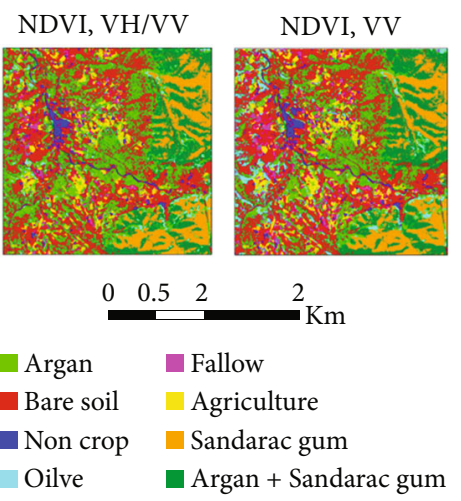

FIgURe 7: Maps resulting from the best classifications.

Table 7 shows the producer accuracy (PA) and user accuracy (UA) of classifications after smoothing.

We ended with the elaboration of three tree species maps (Figure 9), the first one derived from NDVI, the second one derived from the best scenario of SAR data (VH, VH/VV, and texture), and the third one derived from the best scenario of combined data (multisensor data) (NDVI, VV). Finally, as the goal of the present work, we developed the spatial distribution maps of the argan tree and other tree species present in the Smimou zone.

4.3. Discussion. In general, the NDVI profiles model the phenological behavior of the classes, and compared to the $\mathrm{VV}$, $\mathrm{VH}$, and VH/VV profiles, they show a high separability of the classes which facilitates their discrimination when applying the classification algorithms. By quantifying the results using the confusion matrices, the separability was translated by the difference shown by the accuracy statistics (OA and $K$ indices). The highest classification accuracy was recorded for the optical data $(\mathrm{OA}=89.78 \%$ and $K=0.88)$ compared to fused multisensor data $(\mathrm{OA}=88.14 \%$ and $K=0.86)$, while the classification of the best case scenario of SAR data (VH, VH/VV, and texture features) gave an OA of $38.04 \%$ and a $K$ of 0.29 . The PA values of a single SAR classification before the integration of texture features, shown in Table 7 , illustrate that the most misclassified cover types are bare soil,
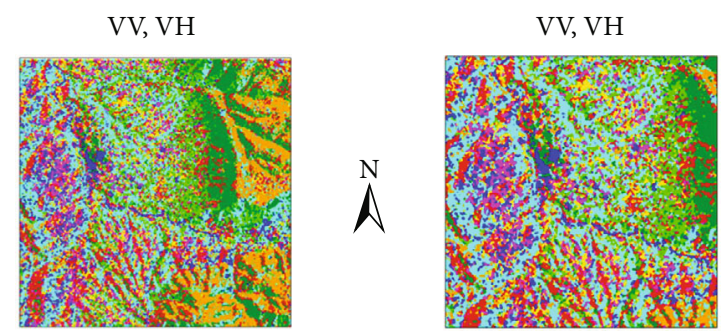

VV, VH, VH/VV

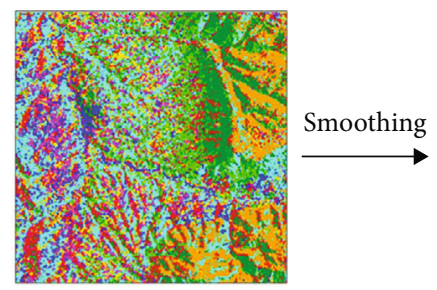

VV, VH/VV, texture
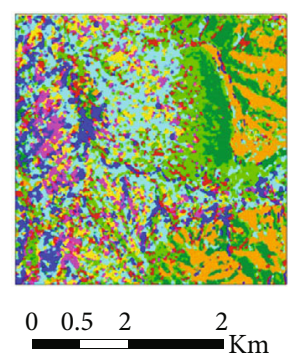

argan Fallow

- Bare soil Agriculture

- Non crop Sandarac gum

Oilve Argan + Sandarac gum

FIgURE 8: Smoothing of scenario classifications (NDVI), (VH and $\mathrm{VV}),(\mathrm{VV}, \mathrm{VH}$, and $\mathrm{VV} / \mathrm{VH})$, and $(\mathrm{VH}, \mathrm{VH} / \mathrm{VV}$, and texture).

TABLE 6: Improvement of $\mathrm{OA}$ and $K$ after application of smoothing.

\begin{tabular}{lcccc}
\hline \multirow{2}{*}{ Scenarios } & \multicolumn{2}{c}{$\begin{array}{c}\text { Before } \\
\text { smoothing }\end{array}$} & \multicolumn{2}{c}{$\begin{array}{c}\text { After } \\
\text { smoothing }\end{array}$} \\
& OA (\%) & $K$ & OA (\%) & $K$ \\
\hline NDVI & 86.90 & 0.84 & 89.78 & 0.88 \\
VV, VH & 33.85 & 0.24 & 35.94 & 0.26 \\
NDVI, VV & 86.51 & 0.84 & 88.14 & 0.86 \\
NDVI, VH/VV & 84.98 & 0.82 & 87.36 & 0.85 \\
NDVI, VH, VV & 77.89 & 0.74 & 81.38 & 0.78 \\
VH, VV, VH/VV & 32.68 & 0.22 & 34.45 & 0.24 \\
NDVI, VV, VH/VV & 80.99 & 0.78 & 83.22 & 0.80 \\
Texture, VH, VH/VV & 37.22 & 0.28 & 38.04 & 0.29 \\
\hline
\end{tabular}

agricultural areas, and argan trees. These confusions can be explained by the fact that the argan trees can be found on cultivated land, in pure forests at different densities, with 


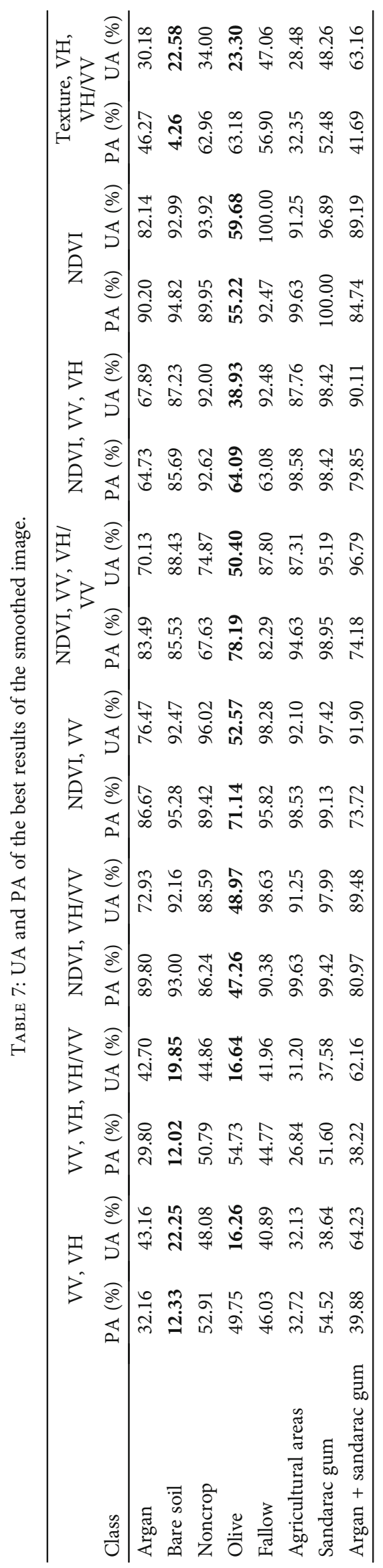




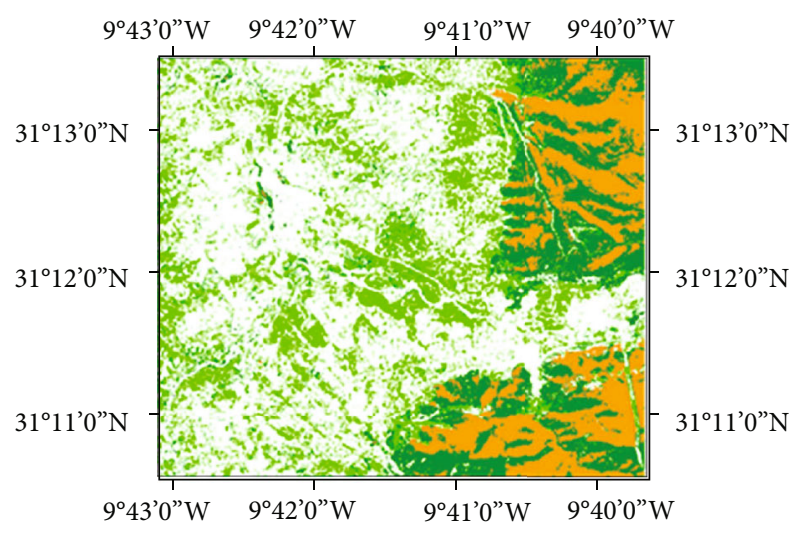

(a)

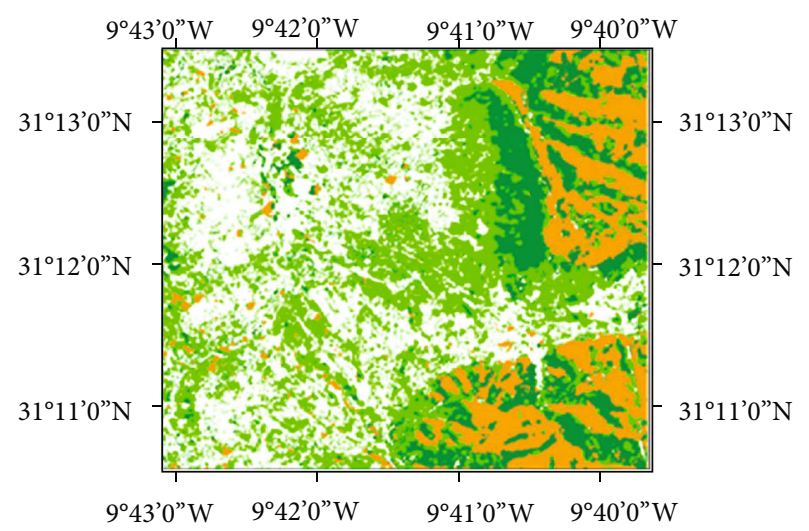

(b)

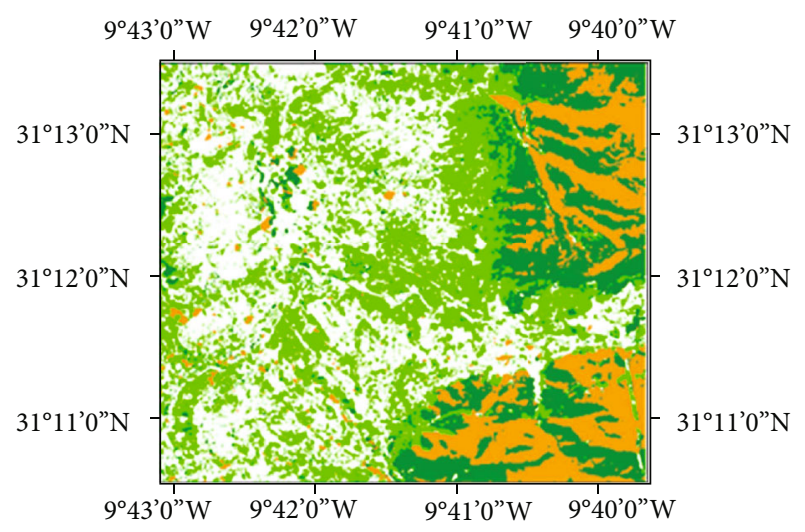

(c)

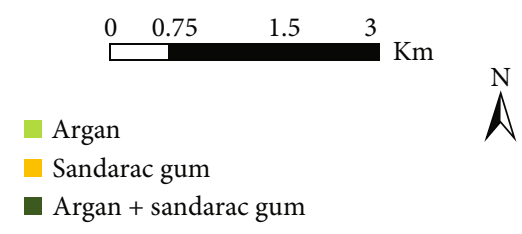

Figure 9: Maps of the spatial distribution of the argan tree using (a) optical data $(\mathrm{OA}=89.78 \%)$, (b) SAR data $(\mathrm{OA}=38.04 \%)$, and (c) combined optical and SAR data $(\mathrm{OA}=88.14 \%)$. or without undergrowth, and in mixed forests. However, the integration of texture features (scenario combining texture, $\mathrm{VH}$, and $\mathrm{VH} / \mathrm{VV}$ ) increased the discrimination of the argan tree $(\mathrm{PA}=46.27 \%$ instead of $\mathrm{PA}=29.80 \%$ and $\mathrm{PA}=32.16 \%$ for the scenarios $\mathrm{VV}, \mathrm{VH}, \mathrm{VH} / \mathrm{VV}$, and $\mathrm{VV}, \mathrm{VH}$, respectively). This confirms the contribution of texture features in the improvement of the tree species classification accuracy using SAR data $[6,8,68,71]$.

On the other hand, concerning the UA values, the olive tree is the most confused tree type (UA value between $16 \%$ and $23 \%$ ). Olive trees in the study area are generally planted around the small villages for local consumption with different densities and with or without annual crops. Therefore, the percentage of UA for bare soil and agricultural areas presents also low values.

For optical classification, the PA and UA values (NDVI time series derived from S2 data) were greater than $70 \%$ for all land covers except for olive trees. The misclassification of this tree type can be explained by the fact that there are some few zones in the study area where argan is mixed with olive trees.

For the fused multisensor data (NDVI, VV which is the best case scenario of combined SAR and optical data), the results of classifications $(\mathrm{OA}=88.14 \%$ and $K=0.86)$ were lower than those of optical classification $(89.78 \%$ and $K=$ $0.88)$, contrary to what was expected $[1,6,85]$. As shown in Table 7, the PA and UA values for the argan tree (PA $=90.20 \%$ and $\mathrm{UA}=82.14 \%$ ), using NDVI classification, are better than those obtained with combined multisensor data $(\mathrm{PA}=86.67 \%$ and $\mathrm{UA}=78.47 \%)$.

However, Sirro et al. [13] used optical and SAR data for forest and land cover classification and revealed that the classification accuracy of optical data was better compared to fused multisensor data. This study aligns with the results that we found in the present study.

S1 and S2 were combined in several studies [86-88] for crop type classification and confirmed that the fusion of the two types of data outperformed the classification based on optical sensor images.

\section{Conclusions}

LC/LU mapping is a crucial tool to understand, analyze, and monitor land cover dynamics in order to better manage territories. Moreover, the availability of satellite imagery, which has the advantage of covering surfaces at all scales (local, regional, and continental), offers the possibility of carrying out this mapping as the only way to monitor large areas, and the principle technical tool put at the service of this discipline. The use of remote sensing data has obvious advantages over land cover classification. The accuracy of these data depends on the quality of information extraction from them, and the combination of optical remote sensing, which includes radiometric indices, with SAR remote sensing is generally accepted as a means of improving classification [89]. The argan tree is an endemic and endangered species in southwestern Morocco. It is a large tree with thorny twigs and attenuated leaves with a short petiole. Since 1998, an area of 830,000 hectares between Agadir and Essaouira has 
had the status of "biosphere reserve" granted by UNESCO to protect the argan tree [90]. In this context, the objective of this study was to map the spatial distribution of the argan tree in the rural community of Smimou using remote sensing data and evaluation of the contribution of the combination of optical and SAR satellite images in improving the identification of the tree species and particularly the argan tree. To do this, we started with data acquisition. 35 Sentinel-2 and 22 Sentinel-1 images were downloaded from THEIA and PEPS websites, respectively, due to the preprocessing already applied to the "ready-to-use" products they offer. In addition, ground truth information was acquired from two field campaigns conducted in 2019, and was supplemented by Google Earth data. The methodology consists of applying the SVM classification of the S2 products, the S1 products, and the combined products of the two sensors, in the following order: the NDVI time series; the time series of $\mathrm{VV}, \mathrm{VH}$, texture, and their combinations; and finally, the time series of the combinations of NDVI, $\mathrm{VV}, \mathrm{VH}$, and the rest. The quantitative evaluation of the results was carried out by the OA and kappa coefficient obtained by construction of the confusion matrices, while the qualities of the images were visually compared in terms of sharpness. A visual interpretation of the quality of the results showed that the classifications of multiband images containing S1 data remain "noisy" despite the fact that these images were filtered before classification. They contain huge spatial expanses of olive trees confused with argan trees. In order to improve the accuracy further, we used the postclassified product smoothing technique. Indeed, the results improved and the classification of the data derived from S1 reached an accuracy of $38.04 \%$ (kappa $=0.29$ ) for the best scenario $(\mathrm{VH}, \mathrm{VH} / \mathrm{VV}$, and texture). Moreover, the synergistic use of the two Sentinel constellation products (1 and 2) led to an increase in terms of accuracy and quality of the map. In perspective, it would be necessary to test the use of $S 1$ and S2 sensors for mapping the spatial distribution of the argan tree over a larger area, i.e., the Essaouira region, and subsequently at the national scale.

\section{Data Availability}

Sentinel-1 and Sentinel-2 images were acquired over the study area and used for the present work. Sentinel-2 images can be downloaded from the following Theia CNES website: https://theia.cnes.fr/. Sentinel-1 data can be downloaded from the following PEPS CNES website: https://peps.cnes .fr/. The SAR imagery was preprocessed using the Sentinel Application Platform (SNAP) and ENVI software.

\section{Conflicts of Interest}

The authors declare that they have no conflicts of interest.

\section{Acknowledgments}

The authors would like to thank the Center of Forestry Research CRF (Centre de Recherches Forestières) for their technical support and accompaniment during field campaigns.

\section{References}

[1] A. Moumni and A. Lahrouni, "Machine learning-based classification for crop-type mapping using the fusion of highresolution satellite imagery in a semiarid area," Scientifica, vol. 2021, Article ID 8810279, 20 pages, 2021.

[2] Y. Yu, M. Li, and Y. Fu, "Forest type identification by random forest classification combined with SPOT and multitemporal SAR data," Journal of Forestry Research, vol. 29, no. 5, pp. 1407-1414, 2018.

[3] R. Touzi, R. Landry, and F. J. Charbonneau, "Forest type discrimination using calibrated C-band polarimetric SAR data," Canadian Journal of Remote Sensing, vol. 30, no. 3, pp. 543551, 2004.

[4] M. M. Rahman and J. T. S. Sumantyo, "Mapping tropical forest cover and deforestation using synthetic aperture radar (SAR) images," Applied Geomatics, vol. 2, no. 3, pp. 113-121, 2010.

[5] R. M. Haralick, K. Shanmugam, and I. H. Dinstein, "Textural features for image classification," IEEE Transactions on Systems, Man, and Cybernetics, vol. SMC-3, no. 6, pp. 610-621, 1973.

[6] A. Masjedi, M. J. Valadan Zoej, and Y. Maghsoudi, "Classification of polarimetric SAR images based on modeling contextual information and using texture features," IEEE Transactions on Geoscience and Remote Sensing, vol. 54, no. 2, pp. 932-943, 2016.

[7] Z. Qi, A. G. O. Yeh, X. Li, and Z. Lin, “A novel algorithm for land use and land cover classification using RADARSAT-2 polarimetric SAR data," Remote Sensing of Environment, vol. 118, pp. 21-39, 2012.

[8] H. Jin, G. Mountrakis, and S. V. Stehman, “Assessing integration of intensity, polarimetric scattering, interferometric coherence and spatial texture metrics in PALSAR-derived land cover classification," ISPRS Journal of Photogrammetry and Remote Sensing, vol. 98, pp. 70-84, 2014.

[9] G. Li, D. Lu, E. Moran, L. Dutra, and M. Batistella, “A comparative analysis of ALOS PALSAR L-band and RADARSAT-2 Cband data for land-cover classification in a tropical moist region," ISPRS Journal of Photogrammetry and Remote Sensing, vol. 70, pp. 26-38, 2012.

[10] J. de Alban, G. M. Connette, P. Oswald, and E. L. Webb, "Combined Landsat and L-band SAR data improves land cover classification and change detection in dynamic tropical landscapes," Remote Sensing, vol. 10, no. 2, p. 306, 2018.

[11] A. L. Mitchell, I. Tapley, A. K. Milne et al., "C- and L-band SAR interoperability: filling the gaps in continuous forest cover mapping in Tasmania," Remote Sensing of Environment, vol. 155, pp. 58-68, 2014.

[12] Y. Yu, M. Li, and Y. Fu, "Forest type identification by random forest classification combined with SPOT and multi-temporal SAR data," Journal of Forestry Research, vol. 29, no. 5, pp. 1407-1414, 2018.

[13] L. Sirro, T. Häme, Y. Rauste et al., "Potential of different optical and SAR data in forest and land cover classification to support REDD+ MRV," Remote Sensing, vol. 10, no. 6, p. $942,2018$.

[14] A. Lapini, S. Pettinato, E. Santi, S. Paloscia, G. Fontanelli, and A. Garzelli, "Comparison of machine learning methods applied to SAR images for forest classification in Mediterranean areas," Remote Sensing, vol. 12, no. 3, p. 369, 2020.

[15] M. Wessel, M. Brandmeier, and D. Tiede, "Evaluation of different machine learning algorithms for scalable classification 
of tree types and tree species based on Sentinel-2 data," Remote Sensing, vol. 10, no. 9, p. 1419, 2018.

[16] E. Raczko and B. Zagajewski, "Comparison of support vector machine, random forest and neural network classifiers for tree species classification on airborne hyperspectral APEX images," European Journal of Remote Sensing, vol. 50, no. 1, pp. 144154, 2017.

[17] A. Lefhaili, FAO Forest Resources Assessment: Morocco Country Report, FAO, Rome, 2010.

[18] F. El Wahidi, Dynamiques des dégradations de l'Arganeraie et modélisation spatiale de l'évolution forestière, Mars, 2013.

[19] Z. Charrouf, H. Harhar, S. Gharby, and D. Guillaume, "Enhancing the value of Argan oil is the best mean to sustain the Argan grove economy and biodiversity, so far," Oléagineux, Corps Gras, Lipides, vol. 15, no. 4, pp. 269-271, 2008.

[20] O. M'hirit, M. Benzyane, and F. Benchekroun, L'Arganier, une espèce fruitière-forestière à usages multiples, Mardaga, 1998.

[21] Z. Charrouf, "20 ans de recherche-action pour faire de l'Arganier un levier du développement durable du milieu rural marocain," in Actes du colloque international, Faculté des Sciences, pp. 3-12, Université Mohammed V-Agdal, Rabat, Maroc, 2007.

[22] F. El Wahidi, R. Bellefontaine, P. Quentin, and P. Defourny, "Dynamique de changement de l'Arganeraie entre sur-usage et mutations sociales: une opportunité d'équilibre socio-écologique?," Journal of Agriculture and Environment for International Development, vol. 108, no. 2, pp. 109-133, 2014.

[23] DREF/SO, Evaluation des travaux de régénération de l'Arganier, Direction Régionale des Eaux et des Forêts du Sud Ouest (Agadir), Haut Commissariat des Eaux et des Forêts et de la Lutte contre la Désertification, 2005.

[24] M. Alifriqui, L'écosystème de l'Arganier. Étude réalisée à la demande du Programme des Nations Unies pour le développement, PNUD-Maroc, 2004.

[25] Z. Charrouf and D. Guillaume, "Argan oil, functional food, and the sustainable development of the Argan forest," Natural product communications, vol. 3, no. 2, 2008.

[26] A. Moumni, B. Sebbar, V. Simonneaux, J. Ezzahar, and A. Lahrouni, "Sample period dependent classification approach for the cartography of crops in the Haouz Plain, Morocco," in Remote Sensing for Agriculture, Ecosystems, and Hydrology XXI vol. 11149, no. article 1114909, 2019International Society for Optics and Photonics, 2019.

[27] A. Moumni, B. Sebbar, V. Simonneaux, J. Ezzahar, and A. Lahrouni, "Evaluation of Sen2agri system over semi-arid conditions: a case study of the Haouz Plain in Central Morocco," in 2020 Mediterranean and Middle-East Geoscience and Remote Sensing Symposium (M2GARSS), pp. 343-346, IEEE, 2020.

[28] B. Sebbar, A. Moumni, and A. Lahrouni, "Decisional tree models for land cover mapping and change detection based on phenological behaviors. Application case: localization of non-fully-exploited agricultural surfaces in the eastern part of the Haouz Plain in the semi-arid Central Morocco," The International Archives of Photogrammetry, Remote Sensing and Spatial Information Sciences, vol. 44, pp. 365-373, 2020.

[29] A. Moumni, M. Oujaoura, J. Ezzahar, and A. Lahrouni, “A new synergistic approach for crop discrimination in a semi-arid region using Sentinel-2 time series and the multiple combination of machine learning classifiers," Journal of Physics: Conference Series, vol. 1743, no. 1, article 012026, 2021.
[30] M. Herold, P. Mayaux, C. E. Woodcock, A. Baccini, and C. Schmullius, "Some challenges in global land cover mapping: an assessment of agreement and accuracy in existing $1 \mathrm{~km}$ datasets," Remote Sensing of Environment, vol. 112, no. 5, pp. 2538-2556, 2008.

[31] A. Fisher, T. Danaher, and T. Gill, "Mapping trees in high resolution imagery across large areas using locally variable thresholds guided by medium resolution tree maps," International Journal of Applied Earth Observation and Geoinformation, vol. 58, pp. 86-96, 2017.

[32] B. El Fasskaoui, "Fonctions, défis et enjeux de la gestion et du développement durables dans la Réserve de Biosphère de l'Arganeraie (Maroc)," Études caribéennes, vol. 12, 2009.

[33] A. Errouati, "Problématique de la régénération assistée et des reboisements à base d'Argania spinosa dans la région du massif forestier d'Amsitten (Province d'Essaouira)," Mémoire de 3ème Cycle, ENFI, Salé, Maroc, 2005.

[34] A. Adlouni, "Place de la nutrition à l'huile d'argan dans la prévention des maladies cardiovasculaires et des cancers au Maroc," Revue Francophone des Laboratoires, vol. 2009, no. 416, p. 34, 2009.

[35] H. Bennani, J. Fiet, and A. Adlouni, "Impact of argan oil on prostate cancer antiproliferative effect: study of polyphenols," Revue Francophone des Laboratoires, vol. 2009, no. 416, pp. 23-26, 2009.

[36] M. Aouragh, "Dynamique du « paysage-arganeraie » dans le Sud-ouest marocain. Apport des données de télédétection et perspectives de les intégrer dans un SIG," in Thèse de doctorat, Université Paris Sorbonne, Paris, 2012.

[37] A. Zahidi, F. Bani-Aameur, and A. El Mousadik, "Growth variability in Argania spinosa seedlings subjected to different levels of drought stress," Journal of Horticulture and Forestry, vol. 5, no. 11, pp. 204-217, 2013.

[38] A. Hachemi, O. S. Ali, T. Belghazi et al., "Effect of hydric and light stress on biomass, nutrient uptake and enzymatic antioxidants of Argania spinosa seedlings," Archives of Biological Sciences, vol. 73, no. 1, pp. 145-153, 2021.

[39] T. Belghazi, Q. Ponette, M. Jonard, and B. Belghazi, Biomasse ligneuse et foliaire des taillis d'arganier 558 dans le plateau des Haha, Maroc, Forêt méditerranéenne, 2016.

[40] R. Mehdioui and A. Kahouadji, "Etude ethnobotanique auprès de la population riveraine de la forêt d'Amsittène: cas de la Commune d'Imi n'Tlit (Province d'Essaouira)," Bulletin de l'Institut scientifique, Rabat, section Sciences de la vie, vol. 29, pp. 11-20, 2007.

[41] M. Drusch, U. Del Bello, S. Carlier et al., "Sentinel-2: ESA's optical high-resolution mission for GMES operational services," Remote Sensing of Environment, vol. 120, pp. 25-36, 2012.

[42] D. Giordan, D. Notti, A. Villa et al., "Low cost, multiscale and multi-sensor application for flooded area mapping," Natural Hazards and Earth System Sciences, vol. 18, no. 5, pp. 14931516, 2018.

[43] F. Gascon, C. Bouzinac, O. Thépaut et al., "Copernicus Sentinel-2A calibration and products validation status," Remote Sensing, vol. 9, no. 6, p. 584, 2017.

[44] N. Baghdadi, M. Leroy, P. Maurel et al., "The Theia land data centre," in In Remote Sensing Data Infrastructures (RSDI) International Workshop, La grande motte, France, 2015.

[45] F. Gascon, E. Cadau, O. Colin et al., "Copernicus Sentinel-2 mission: products, algorithms and Cal/Val," In Earth observing 
systems XIX International, Society for Optics and Photonics, vol. 9218, article 92181E, 2014.

[46] M. Main-Knorn, B. Pflug, J. Louis, and V. Debaecker, "Calibration and validation plan for the L2A processor and products of the Sentinel-2 mission," In Proceedings of International Symposium on Remote Sensing of Environment (ISRSE) 2015, Copernicus Publications, vol. 40, no. W3, pp. 1249-1255, 2015.

[47] M. Main-Knorn, B. Pflug, J. Louis, V. Debaecker, U. MüllerWilm, and F. Gascon, "Sen2Cor for Sentinel-2," in Image and Signal Processing for Remote Sensing XXIII, USA, 2017.

[48] J. Louis, V. Debaecker, B. Pflug et al., "Sentinel-2 Sen2Cor: L2a processor for users," Proceedings Living Planet Symposium 2016, , pp. 1-8, Spacebooks Online, 2016.

[49] C. J. Tucker, "Red and photographic infrared linear combinations for monitoring vegetation," Remote Sensing of Environment, vol. 8, no. 2, pp. 127-150, 1979.

[50] C. Danilla, C. Persello, V. Tolpekin, and J. R. Bergado, "Classification of multitemporal SAR images using convolutional neural networks and Markov random fields," in In 2017 IEEE International Geoscience and Remote Sensing Symposium (IGARSS) IEEE, pp. 2231-2234, IEEE, 2017.

[51] B. Matsushita, W. Yang, J. Chen, Y. Onda, and G. Qiu, "Sensitivity of the enhanced vegetation index (EVI) and normalized difference vegetation index (NDVI) to topographic effects: a case study in high-density cypress forest," Sensors, vol. 7, no. 11, pp. 2636-2651, 2007.

[52] N. Baghdadi, M. Choker, M. Zribi et al., "A new empirical model for radar scattering from bare soil surfaces," Remote Sensing, vol. 8, no. 11, p. 920, 2016.

[53] R. Torres, P. Snoeij, D. Geudtner et al., "GMES Sentinel-1 mission," Remote Sensing of Environment, vol. 120, pp. 9-24, 2012.

[54] A. Veloso, S. Mermoz, A. Bouvet et al., "Understanding the temporal behavior of crops using Sentinel-1 and Sentinel-2like data for agricultural applications," Remote Sensing of Environment, vol. 199, pp. 415-426, 2017.

[55] P. Potin, P. Bargellini, H. Laur, B. Rosich, and S. Schmuck, "Sentinel-1 mission operations concept," in 2012 IEEE International Geoscience and Remote Sensing Symposium, pp. 1745-1748, Germany, 2012.

[56] D. Geudtner, R. Torres, P. Snoeij, M. Davidson, and B. Rommen, "Sentinel-1 system capabilities and applications," in 2014 IEEE Geoscience and Remote Sensing Symposium, pp. 1457-1460, Canada, 2014.

[57] P. Potin, B. Rosich, N. Miranda et al., "Sentinel-1 constellation mission operations status," in In IGARSS 2018 IEEE International Geoscience and Remote Sensing Symposium, pp. 15471550, Valencia, Spain, 2018.

[58] S. Darmawan, I. Carolita, R. Hernawati et al., "The potential scattering model for oil palm phenology based on spaceborne X-, C-, and L-band polarimetric SAR imaging," Journal of Sensors, vol. 2021, Article ID 6625774, 14 pages, 2021.

[59] X. Tang, L. Zhang, and X. Ding, "SAR image despeckling with a multilayer perceptron neural network," International Journal of Digital Earth, vol. 12, no. 3, pp. 354-374, 2019.

[60] H. G. Han and M. J. Lee, "A method for classifying land and ocean area by removing Sentinel-1 speckle noise," Journal of Coastal Research, vol. 102, supplement 1, pp. 33-38, 2020.

[61] J. Zhu, J. Wen, and Y. Zhang, "A new algorithm for SAR image despeckling using an enhanced Lee filter and median filter," in 2013 6th International Congress on Image and Signal Processing (CISP), pp. 224-228, Hangzhou, China, 2013.
[62] A. Gaber, M. Koch, and F. El-Baz, "Textural and compositional characterization of Wadi Feiran deposits, Sinai Peninsula, Egypt, using Radarsat-1, PALSAR, SRTM and ETM+ data," Remote Sensing, vol. 2, no. 1, pp. 52-75, 2010.

[63] S. M. Abuzied, "Groundwater potential zone assessment in Wadi Watir area, Egypt using radar data and GIS," Arabian Journal of Geosciences, vol. 9, no. 7, pp. 1-20, 2016.

[64] Z. Szantoi, F. Escobedo, A. Abd-Elrahman, S. Smith, and L. Pearlstine, "Analyzing fine-scale wetland composition using high resolution imagery and texture features," International Journal of Applied Earth Observation and Geoinformation, vol. 23, pp. 204-212, 2013.

[65] A. Saleem, J. L. Awange, and R. Corner, "Exploiting a texture framework and high spatial resolution properties of panchromatic images to generate enhanced multi-layer products: examples of Pleiades and historical CORONA space photographs," International Journal of Remote Sensing, vol. 42, no. 3, pp. 929-963, 2021.

[66] X. Zhang, J. Cui, W. Wang, and C. Lin, "A study for texture feature extraction of high-resolution satellite images based on a direction measure and gray level co-occurrence matrix fusion algorithm," Sensors, vol. 17, no. 7, p. 1474, 2017.

[67] J. V. Solórzano, J. A. Gallardo-Cruz, and E. J. González, "Contrasting the potential of Fourier transformed ordination and gray level co-occurrence matrix textures to model a tropical swamp forest's structural and diversity attributes," Journal of Applied Remote Sensing, vol. 12, no. 3, article 036006, 2018.

[68] H. Zakeri, F. Yamazaki, and W. Liu, "Texture analysis and land cover classification of Tehran using polarimetric synthetic aperture radar imagery," Applied Sciences, vol. 7, no. 5, 2017.

[69] W. Guo, G. Rees, and A. Hofgaard, "Delineation of the foresttundra ecotone using texture-based classification of satellite imagery," International Journal of Remote Sensing, vol. 41, no. 16, pp. 6384-6408, 2020.

[70] M. Hall-Beyer, "Practical guidelines for choosing GLCM textures to use in landscape classification tasks over a range of moderate spatial scales," International Journal of Remote Sensing, vol. 38, no. 5, pp. 1312-1338, 2017.

[71] F. N. Numbisi, F. M. B. van Coillie, and R. de Wulf, "Delineation of cocoa agroforests using multiseason Sentinel-1 SAR images: a low grey level range reduces uncertainties in GLCM texture-based mapping," ISPRS International Journal of GeoInformation, vol. 8, no. 4, p. 179, 2019.

[72] H. O. Kim and J. M. Yeom, "Effect of red-edge and texture features for object-based paddy rice crop classification using RapidEye multi-spectral satellite image data," International Journal of Remote Sensing, vol. 35, no. 19, pp. 1-23, 2014.

[73] Z. U. Qayyum, A. Akhtar, S. Sarwar, and M. Ramzan, "Optimal feature extraction technique for crop classification using aerial imagery," in 2013 International Conference on Information Science and Applications (ICISA), Thailand, 2013.

[74] D. Deus, "Integration of ALOS PALSAR and Landsat data for land cover and forest mapping in northern Tanzania," Land, vol. 5, no. 4, p. 43, 2016.

[75] V. K. Rana and T. M. Venkata Suryanarayana, "Performance evaluation of MLE, RF and SVM classification algorithms for watershed scale land use/land cover mapping using sentinel 2 bands," Remote Sensing Applications: Society and Environment, vol. 19, p. 100351, 2020.

[76] G. M. Foody and A. Mathur, "Toward intelligent training of supervised image classifications: directing training data 
acquisition for SVM classification," Remote Sensing of Environment, vol. 93, no. 1-2, pp. 107-117, 2004.

[77] T. Kavzoglu and I. Colkesen, "A kernel functions analysis for support vector machines for land cover classification," International Journal of Applied Earth Observation and Geoinformation, vol. 11, no. 5, pp. 352-359, 2009.

[78] S. Abdikan, F. B. Sanli, M. Ustuner, and F. Calò, "Land cover mapping using Sentinel-1 SAR data," The International Archives of Photogrammetry, Remote Sensing and Spatial Information Sciences, vol. 41, p. 757, 2016.

[79] J. Li, Q. Zhu, Q. Wu, and D. Cheng, “An effective framework based on local cores for self-labeled semi-supervised classification," Knowledge-Based Systems, vol. 197, article 105804, 2020.

[80] V. J. Mama and J. O. S. E. P. H. Oloukoi, "Évaluation de la précision des traitements analogiques des images satellitaires dans l'étude de la dynamique de l'occupation du sol," Télédétection, vol. 3, no. 5, pp. 429-441, 2003.

[81] J. A. Cohen, "Coefficient of agreement for nominal scales," Educational and Psychological Measurement, vol. 20, no. 1, pp. 37-46, 1960.

[82] P. M. Mather, Computer processing of remotely-sensed images: an introduction, John Wiley \& Sons Ltd, Chichester, England, 3rd edition, 2004.

[83] N. Torbick, D. Chowdhury, W. Salas, and J. Qi, "Monitoring rice agriculture across Myanmar using time series Sentinel-1 assisted by Landsat- 8 and PALSAR-2," Remote Sensing, vol. 9, no. 2, p. 119, 2017.

[84] D. B. Nguyen, A. Gruber, and W. Wagner, "Mapping rice extent and cropping scheme in the Mekong Delta using Sentinel-1A data," Remote Sensing Letters, vol. 7, no. 12, pp. 1209-1218, 2016.

[85] K. Clauss, M. Ottinger, and C. Kuenzer, "Mapping rice areas with Sentinel-1 time series and superpixel segmentation," International Journal of Remote Sensing, vol. 39, no. 5, pp. 1399-1420, 2018.

[86] K. Van Tricht, A. Gobin, S. Gilliams, and I. Piccard, "Synergistic use of radar Sentinel-1 and optical Sentinel-2 imagery for crop mapping: a case study for Belgium," Remote Sensing, vol. 10, no. 10, p. 1642, 2018.

[87] L. Carrasco, A. W. O’Neil, R. D. Morton, and C. S. Rowland, "Evaluating combinations of temporally aggregated Sentinel1, Sentinel-2 and Landsat 8 for land cover mapping with Google Earth Engine,” Remote Sensing, vol. 11, no. 3, p. 288, 2019.

[88] D. Kpienbaareh, X. Sun, J. Wang et al., "Crop type and land cover mapping in northern Malawi using the integration of Sentinel-1, Sentinel-2, and PlanetScope satellite data," Remote Sensing, vol. 13, no. 4, p. 700, 2021.

[89] A. Achbun, M. Mansour, M. Layelmam, and M. F. Smiej, "Etude comparative de la classification orientée objet d'une image spot5 pour la cartographie de l'occupation du sol via eCognition ${ }^{\circledR}$ 9," GEO OBSERVATEUR, vol. 19, p. 13, 2011.

[90] D. Nill and E. Böhnert, Value chains for the conservation of biological diversity for food and agriculture. Potatoes in the Andes, Ethiopian coffee, Argan oil from Morocco and grasscutters in West Africa. Deutsche Gesellschaftfür Technische Zusammenarbeit, Eschborn, Germany and the Global Facilitation Unit for Underutilized Species, Rome, 2006. 